ISSN 1112-9867

http://www.jfas.info

\title{
PERSUASIVE TECHNOLOGY AS AN INTERVENTION PROGRAMS FOR HEALTH CARE IN MALAYSIA: A REVIEW
}

\author{
N. U. A. Aziz ${ }^{1, *}$, S. M. Salleh ${ }^{1}$, Y. H. M. Yusof ${ }^{1}$ and N. H. M. Roseli ${ }^{2}$ \\ ${ }^{1}$ Faculty of Business Management, Universiti Teknologi MARA, 23000 Dungun, Terengganu, \\ Malaysia \\ ${ }^{2}$ Faculty of Business Management, Universiti Teknologi MARA, Melaka, Malaysia
}

Published online: 10 November 2017

\begin{abstract}
The statistics regarding health problem in Malaysia shows more than $50 \%$ of Malaysian adults have at least one of Non-Communicable Disease. Thus, effort to create awareness as well as promoting mind-set change with regards to health habit is paramount. Researches prove that ICT played significant role in influencing the way of thinking, behaviour and decision making. Intervention programs through computer application should be used to persuade and support health awareness, treatment and prevention. This paper investigate and review studies using persuasive technology in health intervention program in Malaysia. It presents the main objective, the technology persuasive principles and final findings of each study. In conclusion, the application of persuasive technology brings positive impact to awareness creation, aiding prevention and support to change as well as influencing people for a better healthy living.
\end{abstract}

Keywords: persuasive technology; health intervention programs; health care; Malaysia.

Author Correspondence, e-mail: nurul728@tganu.uitm.edu.my

doi: http://dx.doi.org/10.4314/jfas.v9i6s.72 


\section{INTRODUCTION}

In Malaysia the statistics regarding health problem is alarming. Analysis by [10] National Health Morbidity Survey (NHMS) indicates that $63 \%$ of adult aged 18 years and above have at least one Non-Communicable Disease (NCD) such as obesity, overweight, high blood pressures, high blood sugar or high blood cholesterol. Hence, creating awareness and educating the danger of this disease for prevention and treatment is crucial. Recent years have shown that ICT play significant roles in persuading and changing people mind-set, behavior and attitude. A study by [6] have shown that are areas where computing technology and persuasion are overlapping Fig. 1. This shows the big potential of persuasive technology to promote the positive social goals and raise awareness about healthy living, disease prevention and treatment.

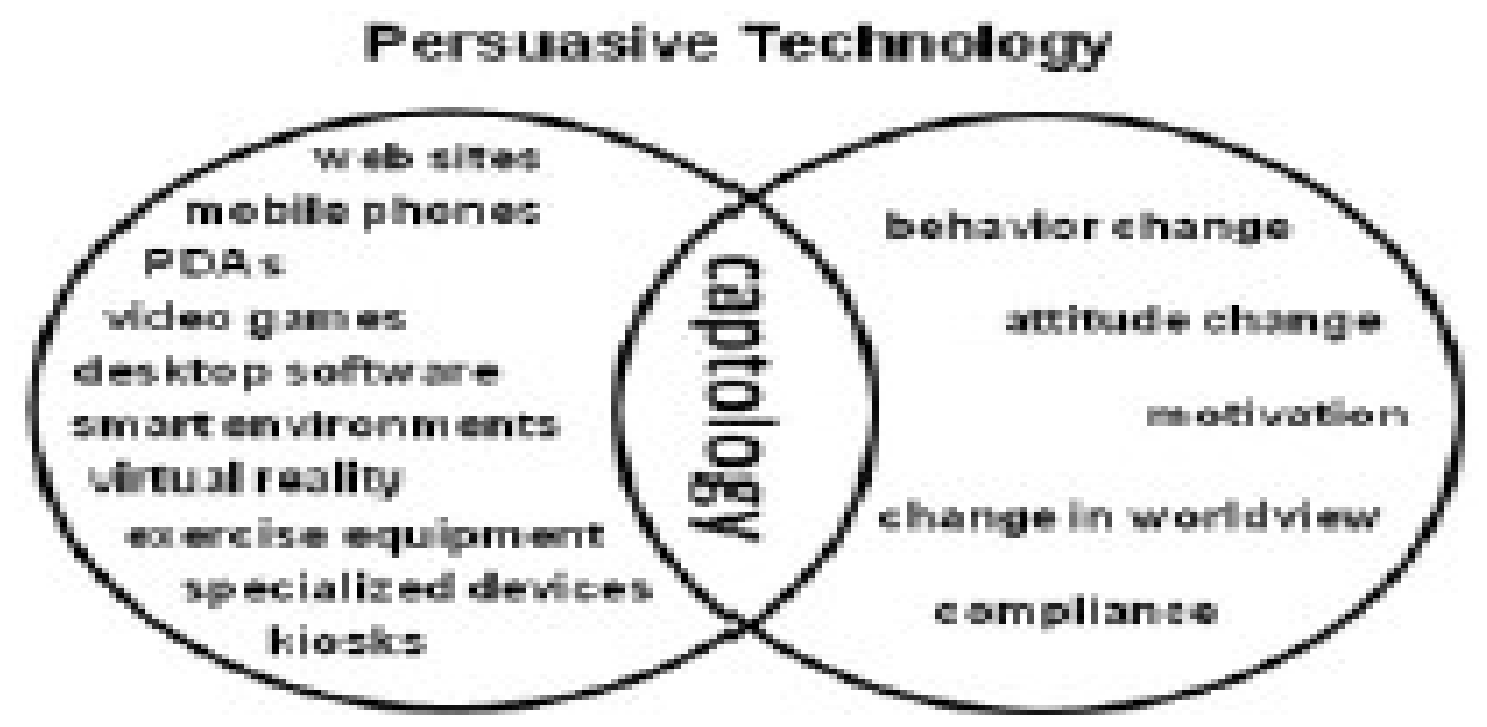

Fig.1. The overlap area between computer and persuasion

The nature of ICT creates opportunity for health provider to reach millions of people within seconds. People can obtain professional advice and trustworthy information without having to visit any health center or hospital. With ICT, people able to receive and update information with minimum effort and at lower cost thus enabling more people to gain access to information regarding health. Statistics in 2015 [8] have shown that computer technology and the use of Internet among Malaysian is $77.6 \%$ (24.1 millions). This fact confirms and supports the idea of ICTs being the most influential tools in conveying knowledge and information to the society. These circumstances in a way lessen the burden of health profession, especially in 
the scope of information distribution, creation of awareness and health prevention. This review focusses on intervention health program in Malaysia and aims to 1) identify previous and current study regarding health intervention program 2) current persuasive technology principles in the health intervention program 3) the findings of the study or program.

\section{METHODOLOGY}

Online Literature research using Google Scholar, EBSChost, ISI Web of Science, Science Direct and ResearchGate is conducted using the search strategy abstracted by the following keyword: Malaysia AND Persuasive Technology AND $<$ health promotion keywords $>$. The search terms were "persuasive technology" AND Malaysia AND "health promotion" OR "health issues" OR "health education" OR "health intervention" OR "Health Intervention Program" OR "Web as Health Intervention Program" OR "Using computer In Health Intervention Program" are adopted. In addition, bibliography from relevant articles, journals and book chapters to identify relevant research are also screened. The date of study ranges from January 2005 to December 2016. All studies written in English and Bahasa Malaysia were included and the keyword search were conducted in June 2017.

\section{RELATED WORK}

\subsection{Children Dental Anxiety}

Children dental anxiety is cause through four major reason which is by own experience of pain also known as direct conditioning, secondhand learning such as negative stories or experienced that is been told or seen, latent behavior and through the behavior of the dentist itself. These factors will contribute to the nervousness feeling when visiting dentist that is known as dental anxiety. To facilitate in overcoming this feeling [1] have design a research on using persuasive design principles in motivational feeling aiming towards Children Dental Anxiety (CDA). This study established an educational material by using CD ROM that involved praise, similarity, virtual rehearsal, social learning and multimedia learning theory. The experimental strategy was tested and evaluated by 240 children from the age seven to nine. The final findings agree that educational material able to give significant positive effects in reducing dental anxiety among children. 


\subsection{Children Awareness of Child Sexual Abuse}

A preliminary investigation about sexual Abuse awareness in Malaysia by [4] is refer as the feedback in relation to the implementation of Persuasive Multimedia Learning Awareness to prevent child sexual abuse. Qualitative method using unstructured interview are been used to gather information about the current children awareness toward sexual abuse and prevention programs implemented in Malaysia. In the interview four respondents was selected; a representative from the Department of Social Welfare, a representative from Women's Centre for Change (WCC) Penang, the Family Law Division, Department of Islamic Affairs Kedah (JAIK) and a primary school teacher. The result reveal that prevention programs in Malaysia is still lacking and children in Malaysia received only limited information. Subsequently, Multimedia Learning Application (MMLA) was design by [5] with the purpose to increase children's awareness of potential sexual abuse situations. The application adopts an instructional design model introduced by Alessi and Troli. Through the beta testing, the MMLA able to facilitate in creating and improving awareness about sexual abuse the application also increases the children understanding about the issues.

\subsection{Stress Awareness}

Stress is a conditioned where emotion, mental and physical becomes tense thus create inability to feel any pleasure experience from activities that normally are enjoyable. This situation can cause depression and other serious medical problems such as disability, morbidity and increase of mortality. In Malaysia, the studies by Association on prevalence of depression among Malaysian show the increase of $50 \%$ from 2011 to 2015 . Hence, one of the effective ways to control the percentage is creating awareness to help prevent depression that occur mostly because of stress. In [12] have design and develop prototype of persuasive multimedia software to increase the awareness on the effects of stress. This research involved three main phases. During the first phases, a simple briefing about the prototype was delivered. Then, in the next phases, the participants were given a questionnaire about Perceive Stress Scale (PSS) to identify their level of stress. For the last phase required the participant to use the application of persuasive multimedia within 20 minutes. In the end, questionnaire regarding Instructional Material Motivation Scale (IMMS) were distributed. The IMMS is used to classify participants' feedback towards the application. Results show that during the 
test participants level of stress is minimal and the IMMS encourage motivation significantly.

\subsection{Childhood Obesity}

Obesity have become one of the serious health concerns among Malaysian, currently Malaysia is rated as the highest among Asia country for Obesity. In [3] have develop a framework of Childhood Obesity Intervention using persuasive mobile game technology. The study proposes the final prototype of mobile game that best match between game and users' needs and expectations. During the study questionnaires were distributed in elementary school in Penang to ensure the compatible of MACO game features and design with the target expectation. At the end of the study, the findings show $72 \%$ believe that MACO game can help lose weight if they know which food is the healthy and unhealthy and $98 \%$ believed that MACO game is fun and entertaining.

Regarding the obesity health concern [7] have also developed an application called MYHEALTHKIDs focusing to create an intelligent obesity intervention system for primary school children. Three modules are use in the application; obesity prediction, children persuasive and last module is recipe suggestion. Naïve Bayes is used to predict the students prone to obese and the persuasive module facilitate in inspiring students to maximize the physical activity and enhance the desire to choose healthy eating habits. The third module uses the principle of knowledge base system that offer ideas for canteen operators to provide healthy servings for the students. In the beginning of the study, a questionnaire that include the parents and student profile, obesity classification and prediction technique is used to predict the likelihood of obesity. This questionnaire is answered by the parents and the information about the risk of obesity was collected to determine the obesity category of each student. To motivate the students to do exercise and physical activity, persuasive module name Encourage Friendly Competition (EFC) is implemented to compare the personal fitness information of each participants while Physical Activities Based Games (PABG) are used to rises the keenness to do physical activities. This game required the player to do more exercises every time when they want to move and play the next stage of the game module. To encourage good healthy dietary behavior module id Persuasive Game (PG) were introduced this module able to intensify the player understanding and change the user way of thinking about healthy eating habits. The final module known as the recipe suggestion designed for 
canteen operators and suggest daily and weekly menu the module include 3 main components; recipe, set meal generation and weekly menu generation. By implementing Case-based reasoning $(\mathrm{CBR})$ and Rule-based reasoning $(\mathrm{RBR})$ technique, each component able to find the best five different level of meals sets daily. Findings proved that MyHealthyKids the prediction of childhood obesity accuracy is around $73.3 \%$ and users agree that the persuasive module able to persuade and change the mindset and habits towards healthy lifestyle among children. Finally, the module of recipe suggestion is considerable relevant ideas to help canteen operators create healthy variation menus for the children.

\subsection{Smoking Cessation}

Smoking is known as one of the most dangerous habits that have become normal among Malaysian. Unfortunately, smoking has become one of the main factor that cause serious health problem such as cancer and heart problem disease. To make it worse, the habits of smoking does not just affect the smokers but also are harmful for the people around the smoker. As an effort to stop this habit, in [13] have develop a research on Persuasive Multimedia Application (PMA) to strengthen motivation to prevent smoking and cessation. The study uses three domains in the forms to plan, evaluate and measured motives using questionnaire as the instrument in the experimental research design. Findings of the analysis indicate that the principle of PMA has stimulate human motivational system and there is significant impact when using redundancy principle in learning using multimedia. PMA is effective towards the solidity for human motivation and reduction principle should be used when delivering the persuasive message.

\subsection{Physical Activity Interventions for Older Adults}

Malaysian government reported that approximately $30-50 \%$ of the healthcare spending is use for the healthcare of older adults. The main attributed to the spending is for the chronic disease such as diabetes, cardiovascular disease and hypertension. The best way to reduce this expenditure is through awareness and prevention. Therefore, a health system named WeSihat was developed in Malaysia to cater older adults. The application is based on touch screen technology integrated with interactive 3D and multimedia elements. Evident show [2] that the application to be well accepted and has successfully enhanced nutritional knowledge among Malaysian adults. The intervention was conducted for 12 weeks involving 65 sarcopenia 
elderly Malay age 64-79 years old. Participant agree that the program is helpful to improved muscle strengthen and body composition besides successful in encouraging physical activity among users respectively Malay [11]. In 2015, a group of researchers [9] reported a review regarding web based physical activity intervention for older adults. It discovered that only two study have shown negative outcomes and subsequently ten studies reveal positive result. Studies reveal that despite the age-related impairments older adults still willing to receive, learn and re-learn using technology application. Web-based interventions main objective of development is to increase and encourage physical activity and not to measures the frequents of physical activity, but focus more on the perceived of acceptance and usability of the web. The strategies that is identifies as among the successful strategies is integrations of personalized tailored feedback, messages or advice base on the needs and preferences of the user. Virtual coach or online consultations with experts as an integration of social roles is reported as one of the effective strategy as it seen able to influence the establishment of trust and confidence towards the web site. The other strategy that contribute to the effectiveness of web sites is the goal setting and action plan that boost self-efficacy and confidence level among the user specifically older adults. According to the Social Cognitive Behavior if a person has self-efficacy they able to change behavior even if they face obstacles. The negative outcomes are being contribute by several factors such as the preference of older adults to choose printed material over web site interface, beside that methodological issue also reveal negative outcomes. Methodological such as the timeframe of the evaluation is too short the limited timespan effect negatively due to unexpected condition such as bad weather that will restrain physical activity. The effectiveness of using ICT in intervention program to encourage physical activity is substantial, but the success rate depends on the characteristics and underlying design strategies.

\section{RESULTS AND DISCUSSION}

To our knowledge, this is the first review about intervention program relating to health care in Malaysia. The comparison, Table 1 shows the summaries about the health concern, persuasive technology principle and the findings. The papers reviewed discuss on the acceptance, potential and effects of persuasive technology towards changing health behavior and increases 
awareness. It shows that persuasive technology in intervention programs concerning health care able to produce positive outcomes towards living a better lifestyle.

Table 1. List of persuasive technology principle in health intervention program in Malaysia

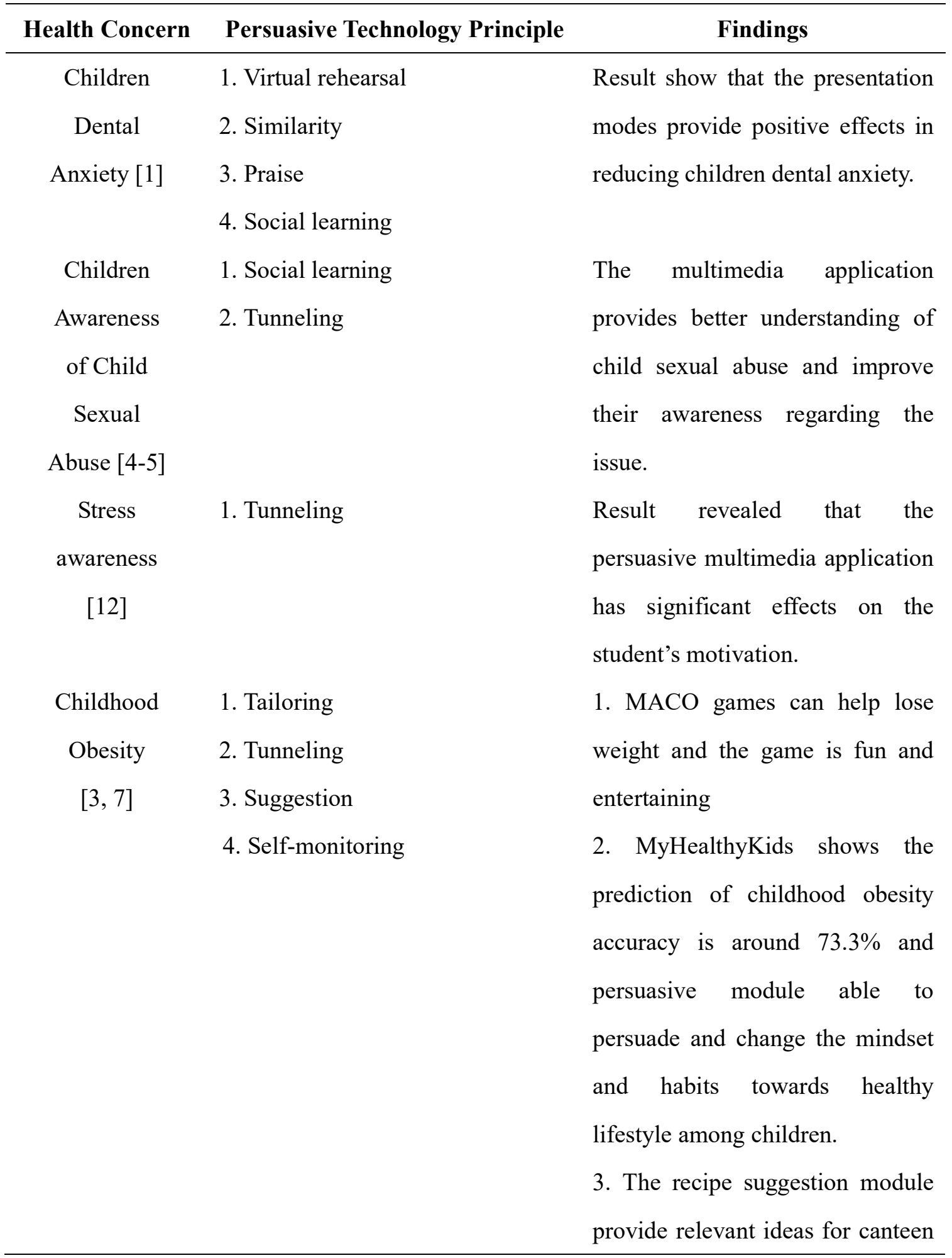


operators to create variety menu.

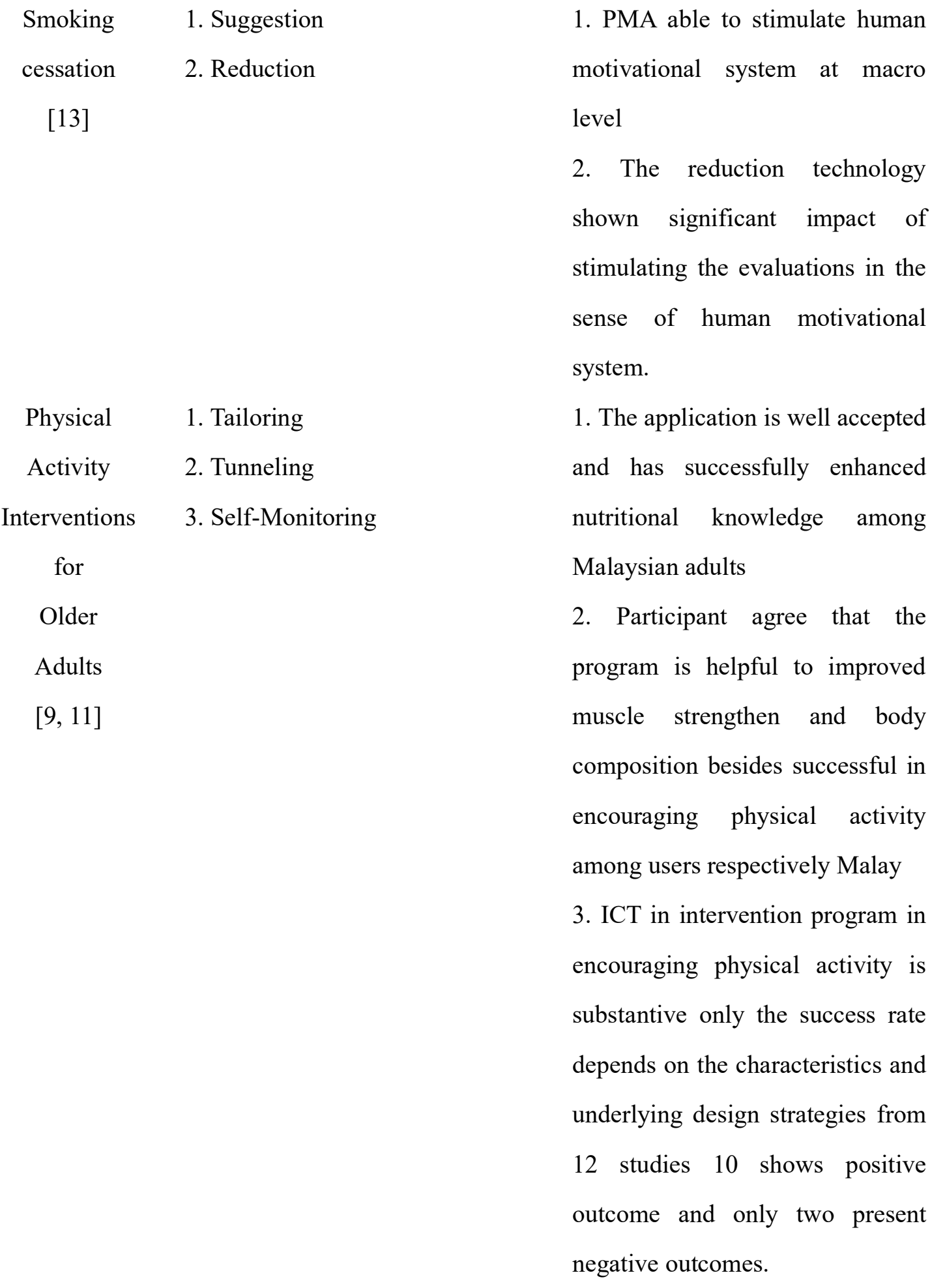




\section{CONCLUSION}

Based on the review, it is concluded that using ICT in health intervention program gives positive impact in creating awareness, changing mind, behavior and motivates people on matters related to health-care. Thus persuasive technology, technique and principle that are appropriate to influence people behavior need to be established as a step to prevent chronic disease occurring among Malaysian. However, it is not conceivable to determine credibility of the effectiveness health intervention program based on studying article, journal and books solely. Based on this review, the number of studies on the application of persuasive technology in health care intervention program in Malaysia is still considered small in numbers as compared to other developed countries but still the findings are hopeful. Future research is necessary to established health care interventions programs to increase the service and effectiveness of public health in Malaysia. Persuasive technology technique and principle need to be identified to provide effective health care services across diverse type of health problem and populations in Malaysia.

\section{REFERENCES}

[1] Salam S, Yahaya W, Ali A M. Using persuasive design principles in motivational feeling towards children dental anxiety (CDA). In 5th International Conference on Persuasive Technology, 2010, pp. 223-237

[2] Ali N M, Shahar S, Kee Y L, Norizan A R, Noah S A. Design of an interactive digital nutritional education package for elderly people. Informatics for Health And Social Care, 2012, 37(4):217-229

[3] Ping L K, Poh J P, Meng L K, Husain W, Adnan M H. A framework of a childhood obesity intervention using persuasive web-mobile technology. In IEEE International Conference on Computer and Information Science, 2012, pp. 50-54

[4] Othman A, Yahaya W A. A preliminary investigation: Children's awareness of child sexual abuse in Malaysia. International Journal of Social Science and Humanity, 2012, 2(3):242-247 
[5] Othman A, Yahaya W A. Multimedia design principles in developing multimedia learning applications (MMLA) to increase children awareness of child sexual abuse. Jurnal Teknologi, 2014, 75(3):7-12

[6] Fogg B. J. Persuasive technology: Using computer to change what we think and do. Massachusetts: Morgan Kaufmann Publisher, 2003

[7] Husain W, Adnan M H, Ping L K, Poh J, Meng L K. Myhealthykids: Intelligent obesity intervention system for primary school children. In 3rd International Conference on Digital Information Processing and Communications, 2013, pp. 627-633

[8] Malaysian Communications and Multimedia Commission (MCMC). Internet users survey 2016-Statistical brief number twenty. Putrajaya: MCMC, 2016

[9] Mohadis H M, Ali N M, Shahar S, Smeaton A F. Web-based physical activity interventions for older adults: A review. In H. Z. Badioze et al. (Eds.), International Visual Informatics Conference. Cham: Springer, 2015, pp. 405-419

[10] Institute for Public Health. National health and morbidity survey 2015: Non-communicable diseases, risk factors and other health problems-volume 2. Putrajaya: Ministry of Health Malaysia, 2015

[11] Shahar S, Kamaruddin N S, Badrasawi M, Sakian N I, Manaf Z A, Yassin Z, Joseph L. Effectiveness of exercise and protein supplementation intervention on body composition, functional fitness, and oxidative stress among elderly Malays with sarcopenia. Clinical Interventions in Aging, 2013, 8:1365-1375

[12] Yahaya W A, Ahmad S N, Zain M Z. Application of persuasive multimedia to raise stress awareness among the secondary school students. IERI Procedia, 2012, 3:105-113 [13] Yahaya W A, Din R C, Hashim M. A future strategy towards smoking cessation: Persuasive Multimedia Application (PMA) in strengthening motivation towards smoking prevention and cessation. In 3rd International Conference on Global Health Challenges, 2014, pp. $37-41$

\section{How to cite this article:}

Aziz N U A, Salleh S M, Yusof Y H M, Roseli N H M. Persuasive technology as an intervention programs for health care in malaysia: a review. J. Fundam. Appl. Sci., 2017, 9(6S), 991-1001. 